pulmonary fibrosis leading to respiratory insufficiency and death; carcinoma of the bronchus; mesothelioma of the pleura or peritoneum; and cancer of the gastrointestinal tract. The hazard appears to be a continuing one, and some risk exists outside the asbestos industry as well as within it. What is not yet sufficiently clear is how much exposure is required in terms of concentration, time, and pattern, to what forms of asbestos fibre, and what the characteristics are of those people who are particularly vulnerable to its ill effects.

Recently P. Enterline and colleagues, ${ }^{8}$ of Pittsburgh, attempted to assess exposure to asbestos dust in a cohort of over 1,300 retired men whose mortality was followed up during 1969. The average length of exposure to it was long, 25 years, and some men had very heavy exposure for a long period. Agecorrected lung cancer mortality rates at the highest level of dust exposure were found to be about three times as high as those at the lowest exposure level. The risk of dying from lung cancer sharply increased at exposures of between 100 and 200 million particles per cubic foot of air-years, and they did not find a direct relationship between exposure and cancer below 125. Analysis showed that both length of exposure and concentration of dust appeared to make independent and similar contributions. However, the difficulty of estimating the dust level with any precision for many different jobs and for years past can be readily appreciated.

These issues and others have now been considered in an important report by the Advisory Committee on Asbestos Cancers to the director of the International Agency for Research on Cancer. ${ }^{9}$ The report follows that produced by the Geographical Pathology Committee of the International Union against Cancer. ${ }^{10}$ The advisory committee was asked to report on the present evidence relating cancers to exposure to asbestos dust and to make recommendations for further research. The report should be studied by all interested in the role of the environment in the production of cancer. In brief, the committee found that there is evidence for a causal relationship but that the risk differs with type of fibre and nature of exposure. The evidence suggests that an excess risk of lung cancer is not detectable when the occupational exposure has been low, and, further, that such low occupational exposures are almost certainly greater than from general air pollution with asbestos. As to mesothelioma, it appears that all commercial types of asbestos may be responsible, but the risk is greatest with crocidolite and less with chrysotile.

The risk from neighbourhood air pollution relates to crocidolite mines and to factories using mixtures of asbestos fibres in conditions which existed many years ago. No excess risk from mesothelioma has been found in the neighbourhood of chrysotile and amosite mines. As regards other cancers, a small excess risk has been shown in occupational groups only. Existing evidence does not indicate any increased risk of cancer from asbestos fibres present in food, drink, or drug fluids. Nor is there any evidence to suggest that pulmonary fibrosis can be caused by asbestos fibres present in the general environment.

Measurements have shown that the amount of asbestos fibre in the lungs of population samples is very small compared with the amount in the lungs of people who have had occupational exposure. But important positive evidence comes from an accumulation of data showing that cigarette smoking enhances the risk of lung cancer in workers exposed to asbestos, and therefore these groups have especially strong reasons for giving up smoking. In contrast, there is no evidence to show that trace metals, waxes, or oils have any similar enhancing effect.

The recommendations made for further research cover a wide field. With the necessary standardization and co-operation answers to urgent problems relating to asbestos should be forthcoming. The committee has indicated those projects it considers rate high in priority.

1 Wagner, J. C., Sleggs, C. A., and Marchand, P., British fournal of Industrial Medicine, 1960, 17, 260.

Newhouse, M. L., and Thompson, H., British fournal of Industrial Medicine, 1965, 22, 261.

${ }^{3}$ Selikoff, I. J., Hammond, E. C., and Churg, J., fournal of the American Medical Association, 1968, 204, 106.

Elmes, P. C., and Simpson, M. J. C., British Fournal of Industrial Medicine, 1971, 28, 226.

${ }^{5}$ Harries, P. G., et al., British fournal of Industrial Medicine, 1972, 29, 274.

${ }^{6}$ Murphy, R. L. H., Ferris, B. G., Burgess, W. A., Worcester, J., and Gaensler, E. A., New England fournal of Medicine, 1971, 285, 1271.

7 Murphy, R. L. H., et al., Archives of Environmental Health, 1972, 25, 253.

8 Enterline, P., DeCoufle, P., and Henderson, V., British fournal of Industrial Medicine, 1973, 30, 162 .

dustrial Medicine, 1973, 30, 162.
British fournal of Industrial Medicine, 1973, 30, 180.

10 British fournal of Industrial Medicine, 1965, 22, 165.

\section{Post-intubation Granuloma}

It could be argued that all the advances in surgical technique of the past thirty years were made possible by the introduction of intratracheal anaesthesia in the 1930s. Further technical improvements have included different substances from which the intratracheal tubes are made, cuffing of the tubes for closed-circuit administration, the structure of gas cylinders, the mechanical delivery of gases in exact proportions, gases of a less lethal nature, and the provision of automatic controls and safety devices. The use of muscle relaxants and controlled mechanically produced respiratory movements followed almost logically. Thus long operations are made possible with little surgical shock and minimal general harm to the patient.

But there is always some price to pay, and one slightly unexpected sequel has been the occurrence, though rarely, of a post-intubation laryngeal granuloma. It is distinct from the lesion that may result from accidental laryngeal trauma during the actual introduction of the tube. This kind of injury can be almost anywhere in the larynx and is usually trivial, causing no permanent damage. Intubation granuloma, however, nearly always occurs on the vocal process of the arytenoid cartilage, which forms the posterior quarter of the total length of the vocal cord. When the patient is supine, the tube comes to lie in the posterior part of the larynx, with its weight resting on the arytenoid cartilages. An area of epithelium (possibly including the perichondrium) may therefore be subjected to friction or to pressure ischaemia and may slough. If the raw surface becomes infected, inflammatory granulation tissue forms, and when spontaneous healing is prevented, perhaps because of lowered vitality in an enfeebled patient, an indolent ulcer may develop, or more often, a localized tumour.

In view of the very large number of intratracheal anaesthetics given, intubation granulomas are rare. Possibly they are more likely to arise when the patient is breathing spontaneously, for then the active movements of the vocal cords could cause friction between the cartilaginous vocal process and the tube. The lesion would seem less likely to develop in an immobile larynx, when a muscle relaxant and controlled respiration are used. Some discussion of the question would be welcome.

Direct laryngoscopy under general anaesthesia and careful removal of the granuloma, under magnification if necessary, is the usual treatment, and it should not befollowed by permanent hoarseness and certainly not by laryngeal stenosis. A. Marshak 
and G. Marshak ${ }^{1}$ were stimulated by a report of success in giving zinc sulphate by mouth to try it in six patients. A 220 mg tablet was given three times a day to the five of them who were adults and $50 \mathrm{mg}$ three times a day to a $3 \frac{1}{2}$-year-old child. The authors say that the treatment should be continued for three or four weeks after the granuloma disappears. They confess ignorance of just how this treatment works, but suggest that it might be given as a prophylactic measure to patients undergoing long operations. No ill effects were reported. As the treatment is simple and apparently harmless it could be tried when surgical endolaryngeal treatment is not available or if for some reason it is considered inadvisable.

1 Marshak, A., and Marshak, G., fournal of Laryngology and Otology, 1973, 87, 573 .

\section{Failure to Respond to Levodopa}

Levodopa is unquestionably the most effective drug available for the treatment of Parkinsonism, but a minority of patients do not obtain any worthwhile benefit from it. There are several reasons for these therapeutic failures.

The commonest problem is that dose-dependent adverse reactions may so dominate the initial results of treatment that they mask any improvement. They can be minimized by introducing levodopa at a low starting dose and increasing it very slowly. Patients should avoid taking the drug on an empty stomach, and the drug should be taken in small doses at frequent intervals, if necessary up to 6 or 7 times over the day. For the first few weeks of treatment the dosage of levodopa has to be varied in accordance with transient adverse effects, such as nausea and hypotension. The necessity for frequent attendances at the clinic and adjustments of dosage comprise a series of hurdles which will be overcome only by firm determination of both physician and patient. Not all complete the course. Patients who are forgetful or unmotivated carry a heavy handicap.

Recent work offers some encouragement to the successful handling of these problems. Extracerebral decarboxylase inhibitors, ${ }^{1}$ when given in combination with levodopa, reduce nausea, so that optimum dosage can be reached more easily and over a shorter period than was previously possible. A different type of difficulty has recently been studied by $R$. J. Mones. ${ }^{2}$ He has coined the term "motor unresponsiveness" to describe an unusual situation in which patients tolerate high dosage of levodopa without any therapeutic effect. Nineteen such patients were identified in a series of 245 with Parkinson's syndrome. Biochemical investigations on six of them confirmed that the drug was being absorbed. In none of these patients was dyskinsia encountered, though that is the commonest limiting adverse reaction to levodopa.

One suggested explanation for "motor unresponsiveness" is that patients with severe Parkinsonism may not have sufficient L-aromatic aminoacid decarboxylase left in their striatum to convert levodopa to dopamine. ${ }^{34}$ However, Mones found that some levodopa was being converted to dopamine in the central nervous system of his unresponsive patients, because the cerebrospinal fluid contained a high concentration of the major metabolite of dopamine, homovanillic acid. Another possibility which should be considered in patients who fail to respond to levodopa is that the diagnosis of Parkinsonism may be incorrect. This can be put in another way: as Parkinsonism is a clinically defined entity, the syndrome due to depletion of dopamine in the striatum can be difficult to distinguish from a number of other conditions which have prominent Parkinsonian features, such as striatonigral degeneration, multiple system atrophy (the Shy-Drager syndrome), and progressive supranuclear palsy (the Steele-Richardson-Olzewski syndrome).

A rare cause of early failure of levodopa therapy is inadequate absorption. This has been reported in one patient. The treatment was to administer antacids. They protect levodopa from metabolism in the stomach. The result was a substantial increase in the plasma concentration of the drug and a corresponding therapeutic response. ${ }^{5}$

Levodopa treatment may fail later because of delayed adverse reactions. In this context postencephalitic patients are particularly vulnerable to psychiatric disturbances. ${ }^{6} 7$ Akinesia paradoxica or intermittent disturbances of voluntary movement may develop, ${ }^{8}$ but seldom within the first 18 months of treatment. Finally, the inexorable advance of the underlying disease of idiopathic Parkinsonism, the pace of which varies greatly in different patients, ${ }^{9}$ gradually erodes the initial benefits of levodopa. The consequent deterioration is not a therapeutic failure in the sense that levodopa is no longer conferring any benefit, for withholding treatment will precipitate an increase of motor disability. These problems merely highlight one of the difficulties in the treatment of many chronic diseases: powerful drugs are available to palliate symptoms, but as the aetiology is unknown the cause of the disease itself is untreatable.

1 Advances in Neurology, ed. M. D. Yahr, vol. 2. New York, Raven Press,

2 Mones, R. J., fournal of Neurology, Neurosurgery, and Psychiatry, 1973,

36, 362.
3 Gerstenbrand, F., in L-dopa and Parkinsonism, ed. A. Barbeau, and F. H. McDowell. Philadelphia, Davis, 1970.

4 Yahr, M. D., in L-dopa and Parkinsonism, ed. A. Barbeau and F. H. McDowell. Philadelphia, Davis, 1970.

${ }^{5}$ Rivera Calimlim, L., Djovne, C. A., Morgan ,J. P., Lasagna, L., and Bianchine, J. R., British Medical fournal, 1970, 4, 93.

6 Hunter, K. R., in Progress in the treatment of Parkinsonism, ed. D. B. Calne. New York, Raven Press, 1973.

7 Sacks, O., Awakenirgs. London, Duckworth, 1973.

8 Barbeau, A., in Proceedings of the 4th International Symposium on Parkin-

Hoehn, M. M., and Yahr, M. D., Neurology, 1967, 17, 427.

\section{Today's Treatment}

As the success of past B.M.F. series of "Today's Drugs" articles has shown, doctors welcome a clear guide to the complex and ever-changing field of medical treatment. This week we start a new series of articles aimed at the nonspecialist doctor with a slightly different emphasis from previous ones-on the management of individual conditions rather than a description of individual drugs and their uses. Each set of articles in the new series will deal with diseases of one body system, and each of these sets will begin with an article on the anatomy and physiology of the system concerned and end with one looking at future propects for new forms of treatment. The first article, printed at page 340 of this week's "Medical Practice," deals with the anatomy and physiology of the skin. 